\title{
Micro and nanocrystalline cellulose based oral dispersible film; preparation and evaluation of in vitro/in vivo rapid release studies for donepezil
}

\author{
Keshireddy AnjiReddy, Subramanian Karpagam ${ }^{(1)}$ \\ Department of Chemistry, School of Advanced Sciences, VIT University, Tamilnadu, India
}

\begin{abstract}
Oral fast-dispersible film was prepared by utlizing donepezil hydrochloride (drug) and various cellulose derivatives such as hydroxypropyl methyl cellulose (hypermellose) (HPMC), microcrystalline cellulose (MCC) and nanocrystalline cellulose (NCC) to treat Alzheimer's disease. NCC was synthesized by ultra-sonication method using MCC and this was converted to thinfilm formulation (NCC-F) using solvent casting technique. The interaction between the polymer and the drug was investigated by spectral analysis such as UV, FTIR, and 1H- NMR. FTIR confirmed that the compatibility of drug and polymer in ODF formulation. NCC-F has shown an average surface roughness of $77.04 \mathrm{~nm}$ from AFM and the average particle size of $300 \mathrm{~nm}$ from SEM analysis. Nano sized particle of NCC-F leads faster in vitro dissolution rate $(94.53 \%)$ when compared with MCC-F and F3 formulation. Animal model (in vivo) studies of NCC-F formulation has reached peak plasma concentration $\left(\mathrm{C}_{\max }\right)$ up to $19.018 \mathrm{ng} / \mathrm{mL}$ in the span of $\left(\mathrm{t}_{\max }\right) 4 \mathrm{~h}$ with greater relative bioavailability of $143.1 \%$. These results suggested that high surface roughness with nanosized NCC-F formulation attained extended drug availability up to $\left(\mathrm{t}_{1 / 2}\right) 70 \mathrm{~h}$.
\end{abstract}

Keywords: Oral dispersible film. Nanocrystalline cellulose. Ultrasonication. 3D atomic force microscopy. Donepezil. Solvent casting. Alzheimer's disease.

\section{INTRODUCTION}

Cellulose is widely used biopolymer on the earth which has linked with $\beta-1,4-\mathrm{D}$ glucose molecules of a homopolymer. Nano crystalline cellulose is a preferable polymer to combine with external moiety through hydrogen bonding to form nano-sized composites. Many literatures are published on extraction of nanosized cellulose from various chemical and mechanical sources for the removal of amorphous part of cellulose using strong acid hydrolysis which results cellulose nanocrystals (Tang et al., 2013). Cellulose nanoparticles was prepared from joint chemical treatment with highintensity ultrasonication (Chen et al., 2011). Based

*Correspondence: S. Karpagam, Department of Chemistry, School of Advanced Sciences, VIT University, Tamilnadu, India. E-mail: skarpagam80@yahoo.com on environmental concern, nano sized cellulose was prepared to use high-cost alternative methods such as acid hydrolysis, ultrasonication, and TEMPOmediated oxidation process (De Campos et al., 2013). Nanocrystalline cellulose was used to control the drug releasing behavior by binding with an active drug moiety (Letchford et al., 2011).

Alzheimer's disease (AD) is a progressive neurodegenerative disorder (Bartha et al., 2007; Brendan et al., 2007) in which patients typically lose cognitive faculties, struggle to carry out activities of daily living and experiencing behavioural and neuropsychiatric problems (Hebert et al., 2003). The frequency of AD increases with age and it affects mainly 65-85 age of people (Molinuevo et al., 2011). At present, there is no curative treatment way for this entity. Currently, there are two types of drugs approved for the symptomatic treatment of patients with $\mathrm{AD}$, the cholinesterase inhibitors (donepezil, galantamine, 
and rivastigmine) and memantine, an antagonist of $\mathrm{N}$-methyl d-aspartate (Atri et al., 2013). After randomized clinical trials of lasting for 6 months, donepezil is approved for all stages of AD in US and Japan (Cheewakriengkrai, Gauthier, 2013). Though, an effective drug, bitter in taste (Lange, Speight, 2005) elder patients find much more difficulty in swallowing the available conventional dosage forms like tablets and capsules. To overcome these problems from the patients, oral disintegrating dosage film formulation has been found. This is a safe, most convenient and cost-effective method of drug formulation with large patient compliance.

The orodispersible films (ODF) was much familiar as an alternative to commercial delivery form in the 1970s (Dixit, Puthli, 2009). On the other hand, the oral disintegrating film is a thin, flexible and transparent strip containing biodegradable and highly hydrophilic polymers, which dissolve quickly on exposure to saliva and disintegrated in the buccal cavity by itself (Abdelbary et al., 2005). To produce thin film, the acrylic and cellulosic polymers like hydroxyl propyl cellulose (HPC) and hydroxyl propyl methyl cellulose (HPMC) have been used through hot melt extrusion technology. The obtained film should qualify all evaluation limits from the process of formulation for the transportation.

Ease of administration is of paramount importance for the dosage forms, especially among patient suffering from schizophrenia, bipolar disorder, Parkinson's disease and Alzheimer disease (Rocca et al., 2002; Rogers et al., 1998). Taste-masked oral disintegrating film was developed which contain donepezil for the treatment of Alzheimer's disease (Nishimura et al., 2009). Earlier preparation includes oral disintegrating film having prochlorperazine, a dopamine D2 receptor antagonist with anti-emetic property using cellulose as the base materials.

Present work deals with the preparation of donepezil oral disintegrating thinfilms (ODF) with different cellulose derivatives like HPMC, MCC, and NCC. Preparation of nanocrystalline cellulose was achieved by ultrasonication followed by centrifugation process from MCC. The phenomenon of making thin ODF was materialized by solvent casting technique and exhibited spectral characteristics like UV, FT-IR, and 1H-NMR respectively for desired formulations. Morphology and particle size were examined by AFM and SEM. In vitro and In vivo drug release profile was highlighted for NCC-F formulation with valid details and compared with other formulation (MCC-F and HPMC).

\section{EXPERIMENTAL PART}

\section{Material and Methods}

Donepezil hydrochloride was received as a gift sample from Dr Reddys laboratory (Hyderabad, India). Hydroxy propyl methyl cellulose $3 \mathrm{cps}$ and 5cps (hypermellose) (HPMC), micro crystalline cellulose (MCC) and carboxy methyl cellulose sodium (CMC sodium) were purchased from Sigma Aldrich., (Bangalore, India). Acesulfame was received from Avra Synthesis Pvt Ltd., (Hyderabad, India). Polyethylene glycol-600 (PEG) was obtained from SD Fine Chemicals Ltd., (Chennai, India). Phosphate buffer salt ( $\mathrm{pH}$ 6.8) was purchased from Fisher Chemicals., (Chennai, India). Oral disintegrating tablet (Aricept $(\circledR)$ ) was used for in vitro and in vivo animal study.

\section{Preparation of nanocrystalline cellulose (NCC)}

Microcrystalline cellulose (MCC) was used for the preparation of nanocrystalline cellulose (NCC) using ultrsonication process (Garvie-Cook et al., 2015). Firstly $1 \mathrm{~g}$ of MCC was taken in $250 \mathrm{~mL}$ of distilled water in a beaker and swelled for $24 \mathrm{~h}$. This was ultrasonicated at $1500 \mathrm{~W}$ output in three different time points 5, 10 and 25 min. After this process, the formed suspension underwent for centrifugation process at $2000 \mathrm{rpm}$ and $4000 \mathrm{rpm}$ for $10 \mathrm{~min}$ each, the obtained supernatant layer was collected, freeze-dried and stored at $5{ }^{\circ} \mathrm{C}$ for further analysis.

\section{Preparation of orodispersible film (ODF)}

Total five different types of ODF formulations were prepared by solvent casting technique using HPMC $3 \mathrm{cps}$ and the drug (F1), HPMC 5cps with the drug (F2), HPMC 5 cps combined with carboxy methylcellulose sodium (F3), MCC-F and NCC-F. All the formulation were represented in Table I. PEG was used as a film former in the preparation and acesulfame was a caloriefree sweetener which used as taste masking agent in the formulation. The active ingredient (drug) was dissolved in $10 \mathrm{~mL}$ of distilled water and stirred for 30 min until it gets clear liquid. On the other hand, cellulose constituents, PEG, glycerol, and acesulfame was homogenized over 30 min. Finally, drug was mixed with polymer solutions and stirred at $1500 \mathrm{rpm}$ for an $30 \mathrm{~min}$. This was allowed for sonication about 15 min to remove entrapped air bubbles inside the formulation. The final solution was transferred 
into a petri plate diameter of $8 \times 8 \mathrm{~cm}^{2}$ and was maintained at room temperature for $24 \mathrm{~h}$. The formed film was carefully removed from the petri plate and cropped into $2 \times 2 \mathrm{~cm}^{2}$ in size. The film was further examined for its physical characterization. Glycerol help to recover the final film from the petri plate. The schematic diagram of the preparation process is shown in scheme 1 .

TABLE I - Formulation composition for oral disintegrating films (ODF)

\begin{tabular}{lccccc}
\hline \multirow{2}{*}{$\begin{array}{l}\text { Ingredients } \\
(\mathbf{m g})\end{array}$} & F1 & F2 & F3 & MCC-F & NCC-F \\
\cline { 2 - 6 } & 5 & 5 & 5 & 5 & 5 \\
\hline Drug & 45 & - & - & - & - \\
HPMC 3cps & 45 (continuing)
\end{tabular}

TABLE I - Formulation composition for oral disintegrating films (ODF)

\begin{tabular}{lccccc}
\hline $\begin{array}{l}\text { Ingredients } \\
\text { (mg) }\end{array}$ & \multicolumn{5}{c}{ Oral disintegrating film } \\
\cline { 2 - 6 } & F1 & F2 & F3 & MCC-F & NCC-F \\
\hline MCC & & & & 45 & - \\
NCC-25 min & - & - & - & - & 45 \\
HPMC 5cps & - & 45 & 40 & - & - \\
CMC sodium & - & - & 5 & - & - \\
PEG-600 & 12 & 12 & 12 & 12 & 12 \\
Glycerol & 2 & 2 & 2 & 2 & 2 \\
Acesulfame & 1 & 1 & 1 & 1 & 1 \\
Water & $15 \mathrm{~mL}$ & $15 \mathrm{~mL}$ & $15 \mathrm{~mL}$ & $15 \mathrm{~mL}$ & $15 \mathrm{~mL}$ \\
\hline
\end{tabular}
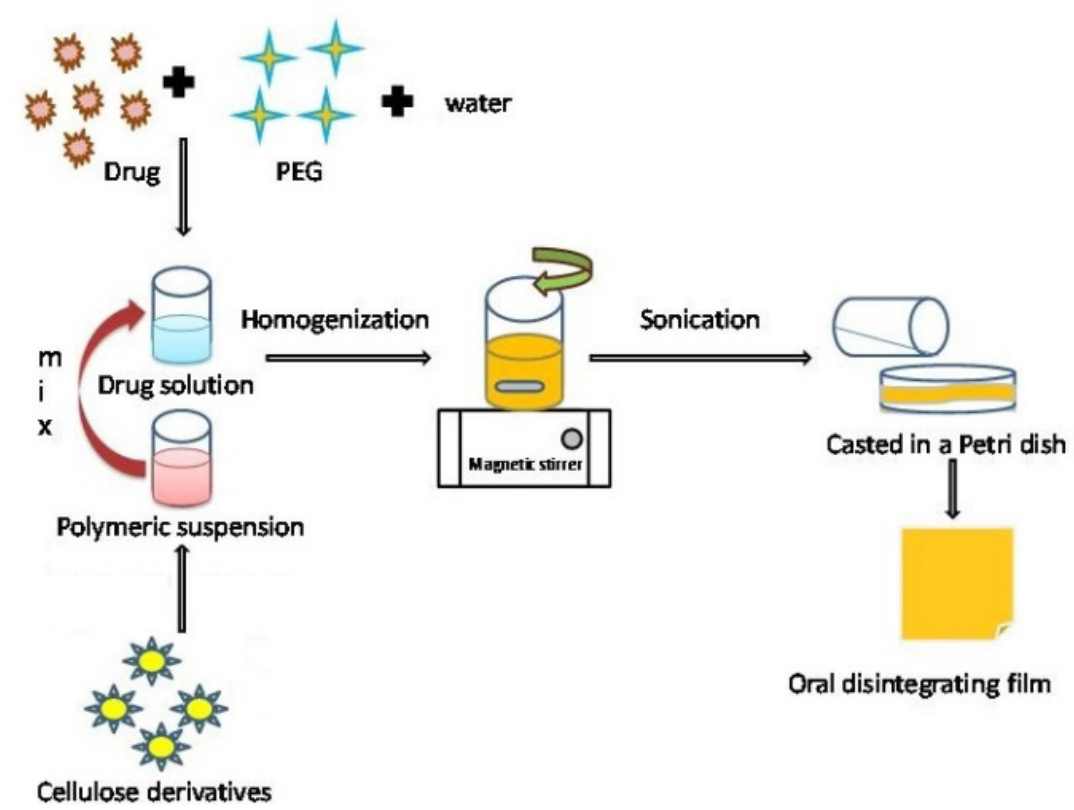

SCHEME 1 - Schematic representation about the preparation of cellulose based ODF.

\section{Spectral Characterization}

Fourier transform infrared (FTIR) spectra was recorded using Thermo Nicolet 330 FTIR spectrophotometer. This was used to determine compatibility between polymer and drug in the ODF formulation in the range of 500-4000 $\mathrm{cm}^{-1}$ using KBR pellet. 1H NMR spectra of oral thin film were recorded withBrukerAVANCEIII 400 MHzusing deuterated water (D2O) as a solvent. Absorption studies were conducted by Hitachi U2910 Ultra-violet (UV) spectrophotometer. Thermo gravimetric analysis (TGA) was carried out 
on TA -dynamic TGA 2950 by maintaining nitrogen atmosphere at a heating rate of $10^{\circ} \mathrm{C}$. Nano surf easy scan-II atomic force microscopy (AFM) instrument was used to characterize surface morphology. Film size of 2 $\times 2 \mathrm{~cm}^{2}$ was allowed to expose in five different locations (centre and four corners). The surface was imaged by tapping mode to elucidate mean roughness. Small pieces of the film was scanned by placing them on a metal stub with a double-sided adhesive layer using Zeiss scanning electron microscope (SEM). Particle size was measured using HORIBA SZ-100 (Japan) dynamic light scattering (DLS) at $25{ }^{\circ} \mathrm{C}$. Each sample was dissolved in $10 \mathrm{~mL}$ deionised water and allowed to run for 3 times using DLS instrument to find Poly dispersity index (PDI) and peak value of particle diameter (nm).

\section{Evaluation parameters of the film}

Five different formulations of drug-loaded cellulose thin film (F1-F3), MCC-F and NCC-F were tested for their visual inspection like appearance, cracks, entrapment of air bubbles inside the film, colour and stickiness of film to petri plate. Surface $\mathrm{pH}$ was measured by placing the electrode on a wet film to find the nature (acidity/alkalinity) of ODF surface. The film thickness is a basic criteria to conclude uniformity at its given strength and measured by Vernier callipers. Thickness was measured in five different locations (centre and four corners) of the film and mean thickness was calculated. The ODF formulation was repeatedly folded at a point until crack and the total number of folds considered as the value of its folding endurance (Rao, Diwan, 1998). Disintegration studies were performed by electro lab disintegration tester using phosphate buffer $(\mathrm{pH}=6.8)$ at $37.0 \pm 0.5^{\mathrm{a}} \mathrm{C}$.

\section{Uniformity of dosage measurement}

Dosage uniformity was determined by highperformance liquid chromatography (HPLC) with spectrometric detection, according to Japanese Pharmacopeia 15th edition. Acceptance value (AV) for the preparation must be less than $15 \%$ and calculated by following equation (Kumar et al., 2014).

Where $\mathrm{M}$ refers to label claim $(100 \%), \mathrm{X}$ is for average (\%) of each content, $\mathrm{k}$ is the acceptability constant (2.2), s refers to standard deviation.

According to United States Pharmacopeia 31, 2010, (Koch et al., 2010) amount of drug in the formulation should be $90-110 \%$ and relative standard deviation should be less than or equal to $6 \%$. A strip of Donepezil oral thin film (5 mg) was dissolved in $100 \mathrm{~mL}$ of $50 \%$ methanol solution. $20 \mu \mathrm{L}$ of sample were injected into HPLC and symmetrical C18 column was employed to estimate the amount of drug. The stability test was determined by storage time in ambient conditions. A small piece of ODF $\left(2 \times 2 \mathrm{~cm}^{2}\right)$ was taken in an aluminium foil and allowed to store for 2-12 weeks at $40{ }^{\circ} \mathrm{C}$ temperature with $75 \%$ humidity (accelerated condition) to find stability under ambient conditions.

\section{Statistical analysis}

All the obtained data were expressed as the mean \pm SD. All the physical evaluations and dissolutions study, all the data were compared statistically. In vitro data of all the formulations were compared and evaluated statistically by Higuchi model and Kosmeyer- Peppas equation (Shoaib et al., 2006).

\section{In-Vitro drug dissolution analysis}

In-Vitro drug dissolution study was carried out using type-II USP dissolution apparatus and $\mathrm{pH} 7.4$ phosphate buffer as dissolution medium with the 900 $\mathrm{mL}$ bath volume. The dissolution test was carried out at $50 \mathrm{rpm}$ at $37 \pm 0.5^{\circ} \mathrm{C}$. The prepared ODF was cut in to a size of $2 \times 2 \mathrm{~cm}^{2}$ and placed in a dissolution basket contains phosphate buffer medium. $5 \mathrm{~mL}$ of sample was taken at specific time intervals $(0-2 \mathrm{~h})$. An equal volume of the dissolution medium was replaced in the vessel after taking sample to maintain sink condition. The concentration of the drug was determined by UVVis spectrophotometer at $232 \mathrm{~nm}$ ( $\lambda$ max of Donepezil hydrochloride). The percentage of drug release at various time intervals was calculated and plotted against time intervals.

\section{In vivo animal studies}

Animal's studies were carried out using Albino Wister rats of 12 to 14 weeks ( 200 to $300 \mathrm{~g}$ ). These rats were maintained with proper diet and stable conditions $\left(12 \mathrm{~h} \mathrm{light} /\right.$ dark at $\left.24 \pm 5{ }^{\circ} \mathrm{C}\right)$. Operating procedure and experiments were approved by the Institutional ethical committee, VIT University, India. Rats were administered at $5 \mathrm{mg} / \mathrm{kg}$ dose of drug via oral route 
and observed for complete degradation of drug in oral cavity. Experimental rats were anesthetized at least 2 to $3 \mathrm{~min}$ before taking blood samples. Sampling procedure was operated by rupturing the orbital plexus of rat in different time intervals starting from $3 \mathrm{~min}, 10 \mathrm{~min}, 15 \mathrm{~min}, 30 \mathrm{~min}$, and $1 \mathrm{~h}$ to $24 \mathrm{~h}$ after the administration of drug. Further blood samples were collected in heparinized tubes and samples were continued for the centrifugation at $10,000 \mathrm{rpm}$ for $5 \mathrm{~min}$. The plasma was separated and stored at -40 to $-70{ }^{\circ} \mathrm{C}$ for further analysis. Plasma samples of each interval were assayed by high performance liquid chromatography (HPLC) method to obtain pharmacokinetic parameters. The HPLC assay was estimated using Waters 1525 instrument (Waters2695 Alliance,USA) with wavelength $(\lambda)$ detection (190 $700 \mathrm{~nm}$ ). Mobile phase consists of $60 \%$ methanol, $40 \%$ $0.02 \mathrm{M}$ phosphate buffer and $0.5 \%$ of triethylamine. Column used was symmetrical C18 $(5 \mu \mathrm{m} 4.6 \times 150 \mathrm{~mm})$ and temperature was set to be $40{ }^{\circ} \mathrm{C}$. All the parameters were calculated by non-compartmental assay using a computer software program (WinOnline1). The peak plasma concentration Cmax $(\mathrm{ng} / \mathrm{mL})$ with respective time bound tmax (h) was evaluated (Sayed et al., 2013). Total drug available throughout the study period and relative bioavailability was calculated from area under curve (AUC $(0-\infty))$. The AUC plasma concentration for $24 \mathrm{~h}(\operatorname{AUC}(0-24))$ upto infinity $(\operatorname{AUC}(0-\infty))$ was measured by trapezoid method with mean \pm SD and statistical significance $(\mathrm{p} \leq 0.05)$.

\section{RESULTS AND DISCUSSION}

Fast dissolving orodispersible film (ODF) was prepared by solvent casting technique using Donepezil hydrochloride as a drug and cellulose derivatives as a polymer for the treatment of Alzheimer disease. The film was characterized using UV, FTIR, and NMR spectrophotometer.

\section{Physical characteristics of ODF formulations}

ODF formulations were evaluated for their physical characteristics, which is mentioned in Table II. All the formulations were appeared to be transparent and translucent for naked eye visuals. Optimum thickness of all formulations were found to be $220 \mu \mathrm{m}$. The mechanical strength of ODF formulations was revealed by folding endurance that was 34 to 43 . Drug content of all the formulations were examined which was agreed well with the standard data of acceptance value (13.8\%). The surface $\mathrm{pH}$ of ODF was found to be neutral for all formulations and this was safe for oral mucosa (Liew et al., 2011). Initially, disintegration time was $13 \mathrm{sec}$ and complete disappearance of the particles in the solution was observed at $42 \mathrm{sec}$ for NCC formulations. These obtained results were ideal for rapid disintegration phenomena and help to promote the onset of drug releasing action (Yamamoto et al., 2009). From the stability measurements (2-12 weeks), the percentage of donepezil hydrochloride was observed to be $95.5 \%$

TABLE II - Physical evaluation parameters of ODF formulation

\begin{tabular}{lcccccc}
\hline $\begin{array}{l}\text { Formulation } \\
\text { code }\end{array}$ & $\begin{array}{c}\text { Thickness } \\
\mathbf{( m m})\end{array}$ & $\begin{array}{c}\text { Folding } \\
\text { endurance }\end{array}$ & Surface $\mathbf{~ p H}$ & $\begin{array}{c}\text { Weight of } \\
\text { film } \mathbf{( m g )}\end{array}$ & Appearance & $\begin{array}{c}\text { Disintegration } \\
\text { time (sec) }\end{array}$ \\
\hline F1 & $0.21 \pm 0.5$ & $33.29 \pm \mathbf{1 . 0 5}$ & $6.8 \pm \mathbf{0 . 2 5}$ & $22.54 \pm \mathbf{1 . 1 5}$ & translucent & $35 \pm 0.05$ \\
F2 & $0.22 \pm 0.5$ & $35.58 \pm 1.07$ & $6.8 \pm 0.45$ & $20.58 \pm 1.07$ & translucent & $45 \pm 0.5$ \\
F3 & $0.22 \pm 0.5$ & $39.45 \pm 1.04$ & $6.9 \pm 0.01$ & $21.45 \pm 1.24$ & translucent & $50 \pm 0.49$ \\
MCC-F & $0.22 \pm 05$ & $37.77 \pm 1.05$ & $6.8 \pm 0.05$ & $25.88 \pm 1.05$ & translucent & $46 \pm 0.05$ \\
NCC-F & $0.21 \pm 0.5$ & $42.73 \pm 1.05$ & $6.8 \pm 0.05$ & $22.73 \pm 1.5$ & translucent & $42 \pm 0.5$ \\
\hline
\end{tabular}

Note: All experiments were done in triplicate; P value of less than 0.05 . 
to $99.1 \%$. Physical evaluations of all the formulations were showed acceptable results for desired drug release (Saluja et al., 2013).

\section{Spectral evaluations of ODF}

UV spectra of drug and ODF formulations were shown in Figure 1. From the UV spectra of the drug, the broad absorption peak was formed at 232 and $320 \mathrm{~nm}$. This was shifted to 230-235 and 315-320 nm in the ODF which was responsible for $\varpi-\varpi^{*}$ transition occurred in aromatic conjugates of the drug. This was confirmed that the presence of drug in the formulated ODF. Maximum absorption wavelength for the drug (232 nm) was taken for further drug dissolution studies.

FT-IR was carried out to identify the functional groups and its characteristic vibrations involved in oral thin film formulations (Shen et al., 2013). The FTIR spectrum of ODF formulation (F2, F3) was shown in Figure 2. The F2 and F3 formulated films were showed broad peak at 3328 and $3365 \mathrm{~cm} \mathrm{-1} \mathrm{that} \mathrm{was} \mathrm{assigned} \mathrm{to}$ $\mathrm{O}-\mathrm{H}$ stretching vibration for the cellulose polymer. The
$\mathrm{C}=\mathrm{O}$ stretching peak was clearly observed in $1681 \mathrm{~cm}^{-1}$ for pure drug molecules. $\mathrm{C}-\mathrm{H}$ stretching vibration was seen at 2890-2922 $\mathrm{cm}^{-1}$ and C-N stretching of tertiary amine has appeared at 1315-1265 $\mathrm{cm}^{-1}$. Considering all these results, there could be possible of hydrogen bond interactions between drug and polymer. The intensity of donepezil hydrochloride was decreased after formulation due to the electrostatic interaction between drug and polymer which allows a high degree of dissolution. Figure 3 represents the 1H NMR spectra of F2 and F3 ODF formulation. Two parts of peak signal were observed for the ODF formulation (F2 and F3). Former part was assigned for the $\mathrm{OH}$ contained polymer and was found at a region of $4.7 \mathrm{ppm}$. Later part was ascribed for the aromatic and alkyl protons of the drug which was observed at $7.24 \mathrm{ppm}$ and 2.7$3.7 \mathrm{ppm}$ respectively. The presence of another band at $2.15 \mathrm{ppm}$ was due to acetyl protons which was present in the ODF (F2 and F3). These results confirm that the drug and polymer interacted with hydrogen bonding to enable the drug to release quickly and may aim for rapid disintegration (Song et al., 2015).

TABLE II - Physical evaluation parameters of ODF formulation

\begin{tabular}{lcccccc}
\hline $\begin{array}{l}\text { Formulation } \\
\text { code }\end{array}$ & $\begin{array}{c}\text { Thickness } \\
\mathbf{( m m})\end{array}$ & $\begin{array}{c}\text { Folding } \\
\text { endurance }\end{array}$ & Surface pH & $\begin{array}{c}\text { Weight of } \\
\text { film (mg) }\end{array}$ & Appearance & $\begin{array}{c}\text { Disintegration } \\
\text { time (sec) }\end{array}$ \\
\hline F1 & $0.21 \pm 0.5$ & $33.29 \pm \mathbf{1 . 0 5}$ & $6.8 \pm \mathbf{0 . 2 5}$ & $22.54 \pm \mathbf{1 . 1 5}$ & translucent & $35 \pm 0.05$ \\
F2 & $0.22 \pm 0.5$ & $35.58 \pm 1.07$ & $6.8 \pm 0.45$ & $20.58 \pm 1.07$ & translucent & $45 \pm 0.5$ \\
F3 & $0.22 \pm 0.5$ & $39.45 \pm 1.04$ & $6.9 \pm 0.01$ & $21.45 \pm 1.24$ & translucent & $50 \pm 0.49$ \\
MCC-F & $0.22 \pm 05$ & $37.77 \pm 1.05$ & $6.8 \pm 0.05$ & $25.88 \pm 1.05$ & translucent & $46 \pm 0.05$ \\
NCC-F & $0.21 \pm 0.5$ & $42.73 \pm 1.05$ & $6.8 \pm 0.05$ & $22.73 \pm 1.5$ & translucent & $42 \pm 0.5$ \\
\hline
\end{tabular}

Note: All experiments were done in triplicate; $\mathrm{P}$ value of less than 0.05 . 


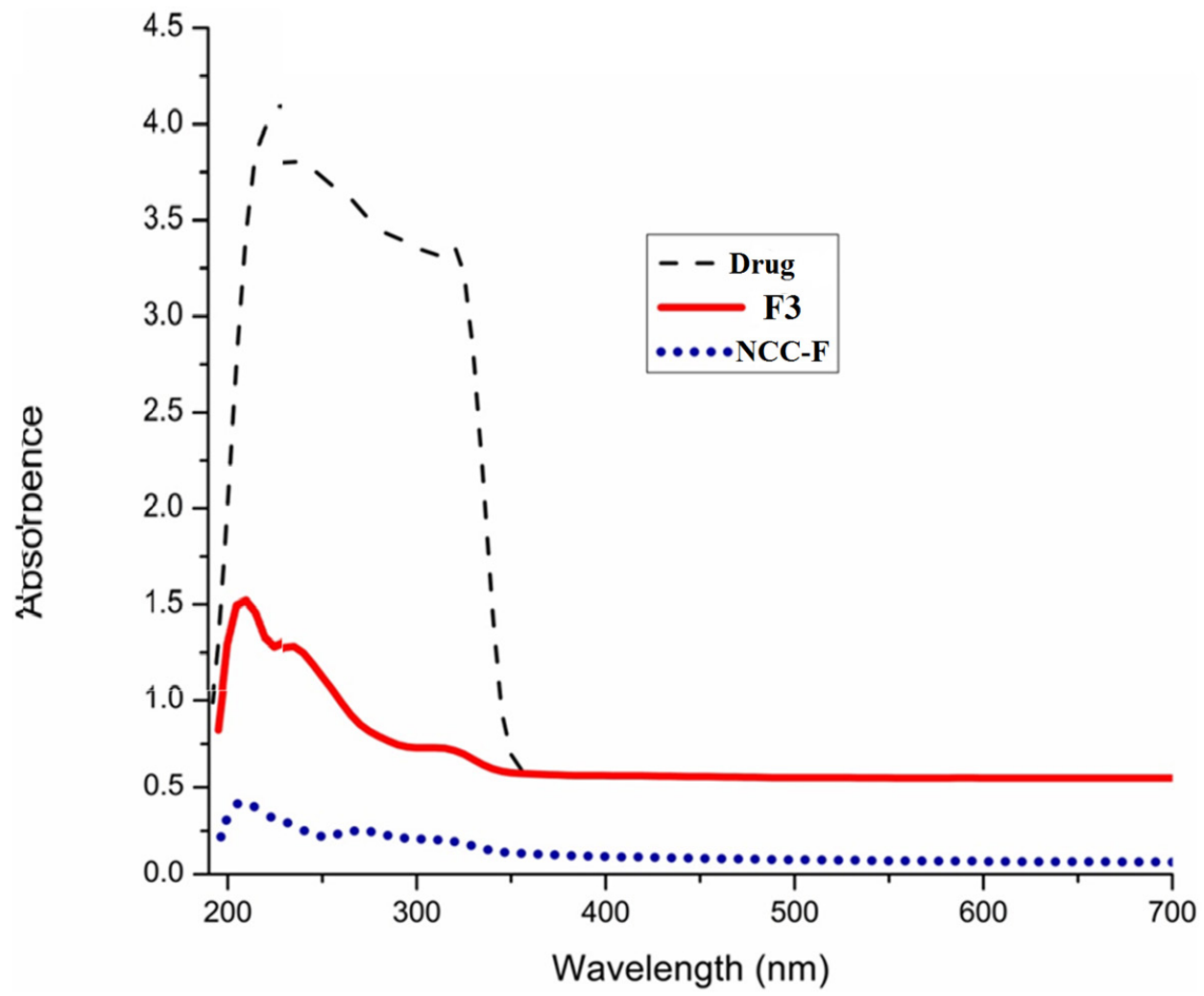

FIGURE 1 - UV absorption spectra of pure drug and oral dispersible film.

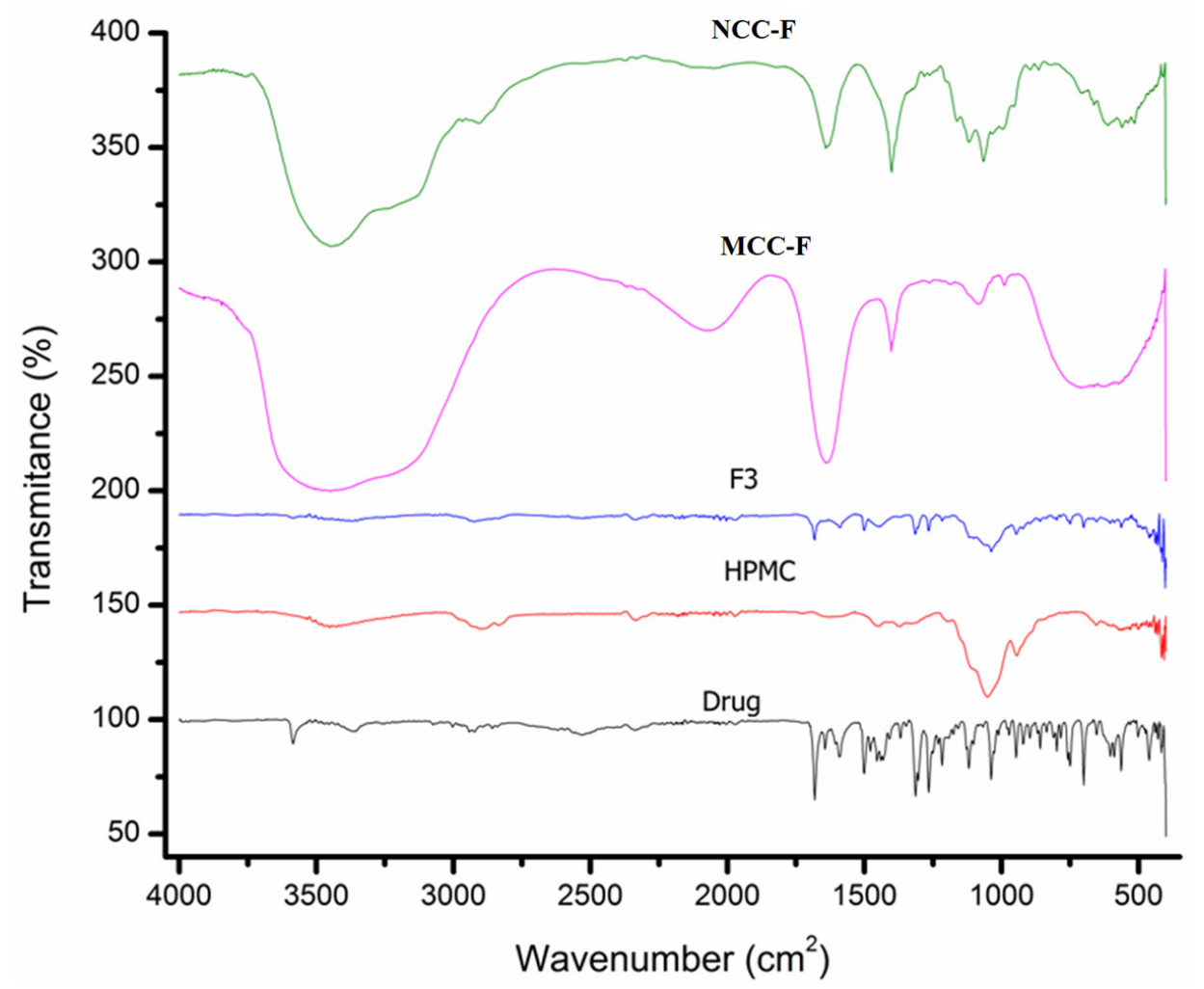

FIGURE 2 - FTIR images of pure drug and various sizes of cellulose mixed Oro dispersible films 


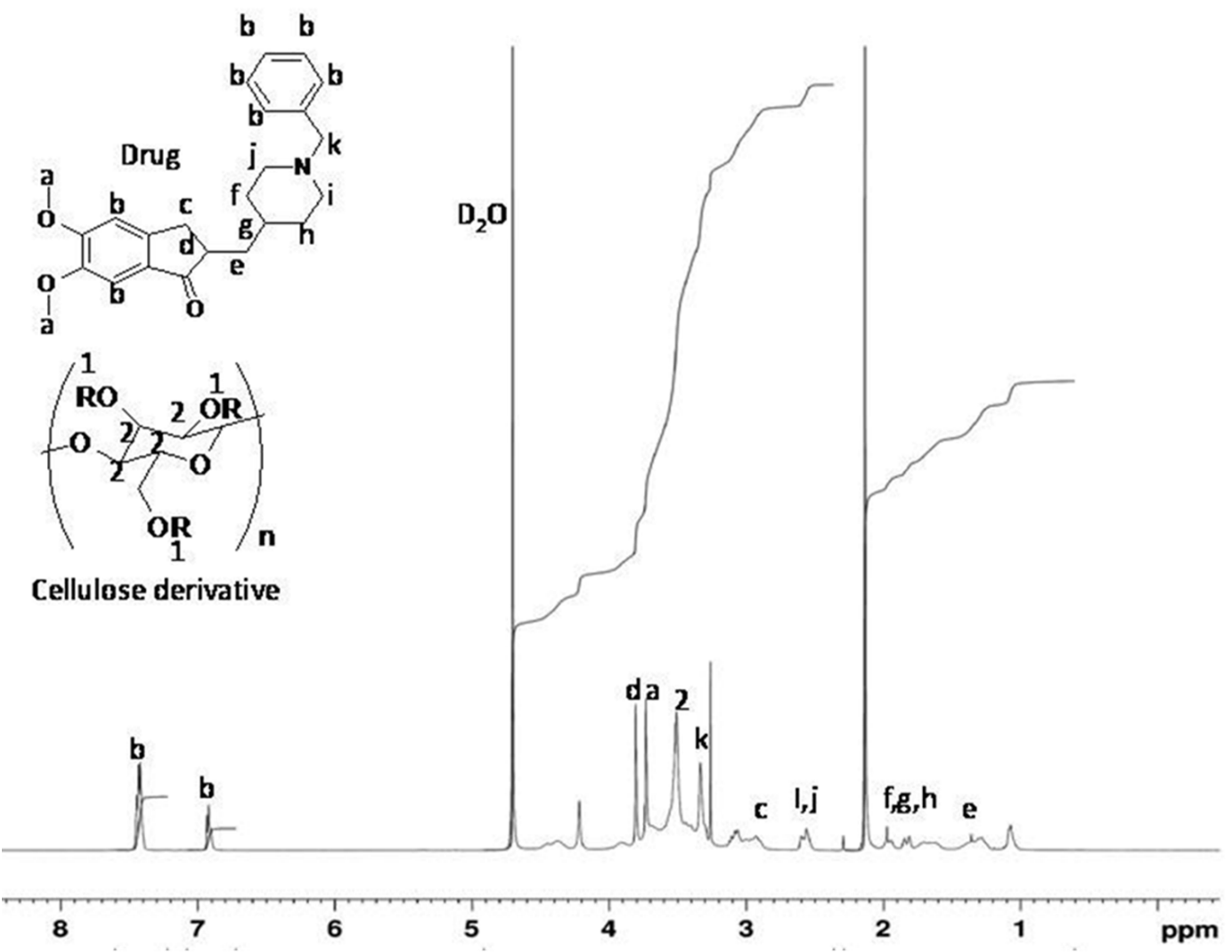

FIGURE 3 - 'H NMR spectra of cellulose mixed ODF (HPMC-F3).

\section{Thermo gravimetric analysis (TGA)}

ODF formulations were tested for their thermal stability in a range of $\left(200-800{ }^{\circ} \mathrm{C}\right)$ temperature. Figure 4 represents the TGA thermo gram of the three ODF formulations. This was carried out under nitrogen atmosphere with constant heating at a rate of $10{ }^{\circ} \mathrm{C}$ (Gaisford et al., 2009). The onset thermal decomposition of the film HPMC, MCC-F, NCC-F was observed at 230, 239 and $274{ }^{\circ} \mathrm{C}$ respectively with a weight loss of 6,9 and $13 \%$. This confirms that all ODF formulations were showed optimum thermal stability. Final decomposition temperature for the three formulations were observed at 408, 410 and $355^{\circ} \mathrm{C}$ respectively. The thermal stability of HPMC contained F3 film was lower due to the weak interaction between drug and polymer. The final weight loss of ODF formulations were 71, 72.2 and 53\% for HPMC, MCC-F, and NCC-F respectively. The HPMC and MCC-F showed comparatively higher \% weight loss than NCC-F film. Overall, the thermal stability of NCC-F was studied at $274{ }^{\circ} \mathrm{C}$ when compared to HPMC and MCC-F formulation.

\section{Atomic force microscopy (AFM)}

Prepared formulations were examined for surface morphology by AFM technique. The AFM topography results in different parameters such as average surface roughness $(\mathrm{Sa})$, root mean square surface roughness (RMS) and maximum peak-valley (Sp-Sv). The results of all prepared formulations and their surface measurements were mentioned in Table III. The NCC-F formulation was showed high porous surface which influence the drug release property. From the AFM images (Figure 5), NCC-F showed higher surface roughness $(77.04 \mathrm{~nm})$ than MCC-F $(74.65 \mathrm{~nm})$ and F3 $(75.3 \mathrm{~nm})$ and RMS roughness was observed to be 50.265 $\mathrm{nm}$. These results may help to predict the drug release character. Higher surface roughness, more porosity of the film may enhance the drug mobility and transport characteriestics (Palla-Papavlu et al., 2014). More porous and surface roughness may allow water molecules to penetrate, which enhance rapid disintegration of drug (Scoutaris, 2012). 


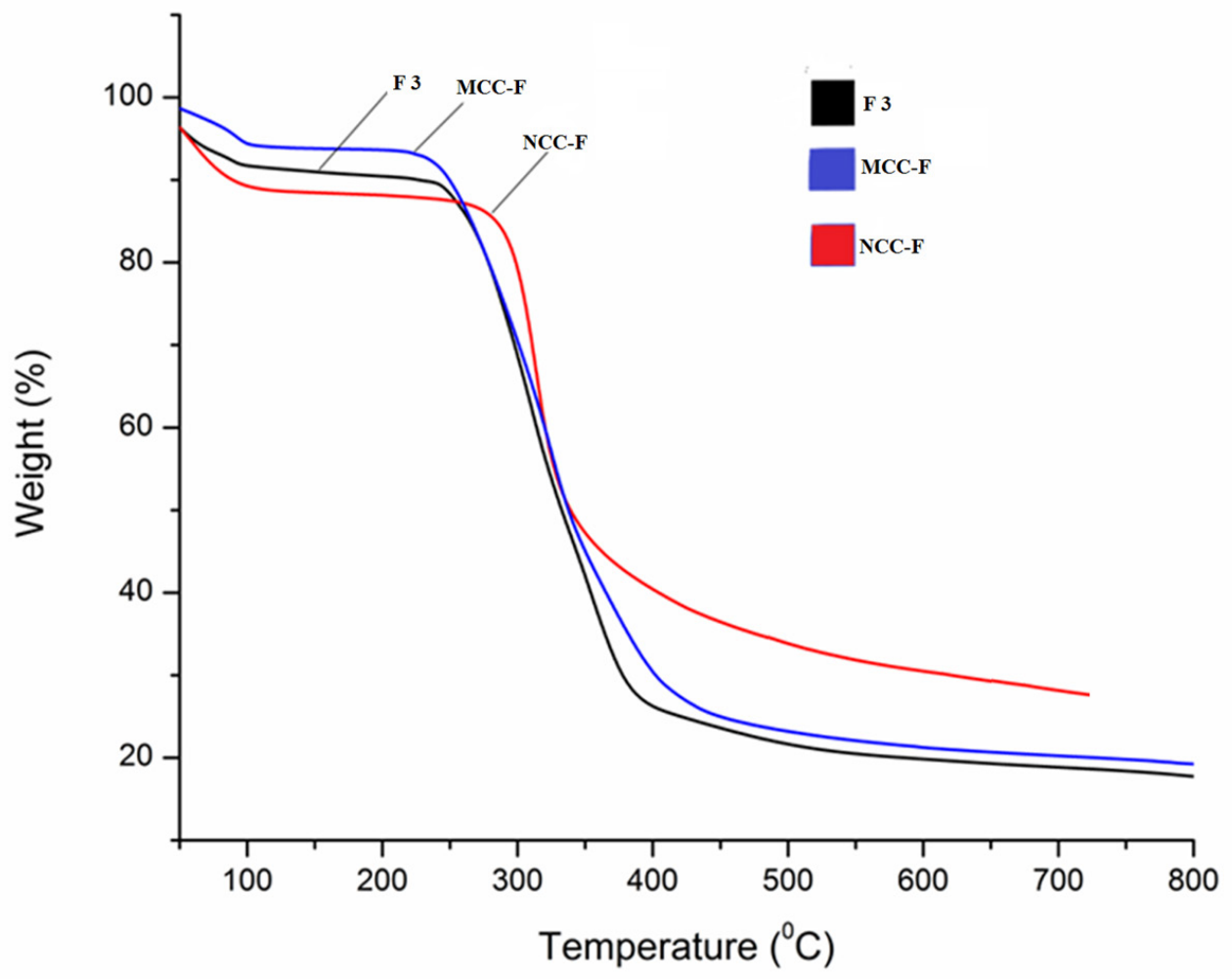

FIGURE 4 - TGA thermo gram of HPMC, MCC-F and NCC-F formulation.

TABLE III - Atomic force microscopy parameters for ODF formulations

\begin{tabular}{|c|c|c|c|c|c|}
\hline Formulation Code & F1 & F2 & F3 & MCC-F & NCC-F \\
\hline $\begin{array}{l}\text { Average surface } \\
\text { roughness }(\mathrm{Sa})(\mathrm{nm})\end{array}$ & 36.833 & 40.189 & 75.343 & 74.654 & 77.004 \\
\hline $\begin{array}{l}\text { RMS roughness } \\
(\mathrm{Sq})(\mathrm{nm})\end{array}$ & 47.865 & 53.177 & 104.35 & 89.99 & 50.265 \\
\hline $\begin{array}{l}\text { Peak-peak height } \\
\text { (Sy) (nm) }\end{array}$ & 411.42 & 439.47 & 1315.5 & 7693.5 & 679.59 \\
\hline $\begin{array}{l}\text { Maximum peak } \\
\text { height }(\mathrm{Sp})(\mathrm{nm})\end{array}$ & 170.63 & 200.92 & 654.82 & 527.98 & 186.33 \\
\hline $\begin{array}{l}\text { Maximum peak } \\
\text { Valley depth (Sv) (nm) }\end{array}$ & -240.78 & -238.55 & -660.73 & -687.11 & -493.26 \\
\hline
\end{tabular}



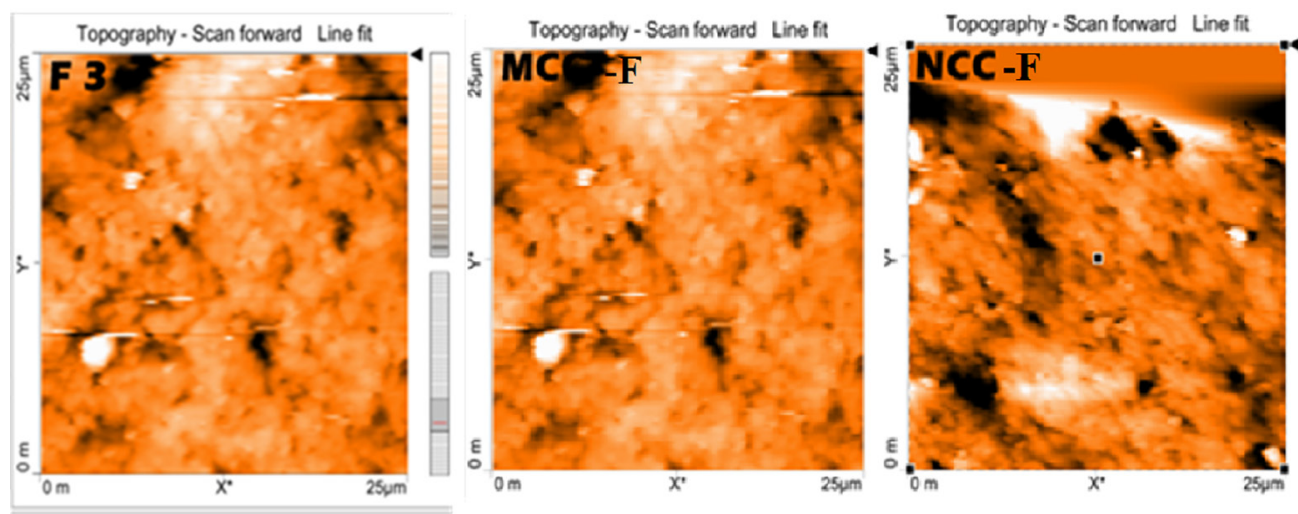

FIGURE 5 - AFM images of F3, MCC-F and NCC-F formulation.

\section{Scanning electron microscope}

Scanning electron microscope (SEM) was performed for the prepared formulations to characterize its particle size and morphology. Figure 6 represents SEM images of formulated ODF. It was showed that F1 and F2 formulations were rough surface with irregular shaped particle sizes, but F3 showed smooth appearance with spherical shaped particles. The sizes of particles were found to be 30, 37 and $50 \mu \mathrm{m}$ for F1, F2, and F3 respectively. From the images the MCC-F, irregular and spherical shaped particles were found with unclear fragmentation. The average particles size was found to be $10 \mu \mathrm{m}$. As can be seen from NCC-F images, the particles were spherical and clear due to ultrasonic treatment. The length of crystals was dependent on ultrasonication time and its duration. The average particle size of nano-cellulose was $300 \mathrm{~nm}$. The emission of heat and excited species via the cavitation effect can relax the MCC surface and lead to bond breakages, thus the ultrasonic impact will gradually disintegrate the micron sized MCC into nano sized NCC (Nishimura et al., 2009).

\section{Particle size analyzer}

The results of peak diameter and polydispersity index were mentioned in table IV. As mentioned in table each value of peak diameter was decreasing with increasing ultrasonication time of NCC sample. Sample with maximum utrasonication time point $25 \mathrm{~min}$ (NCC) has lowest peak value $(2.1 \mathrm{~nm})$. It is clear from Figure 7, that ultrasonication time has direct effect on polydspersity of particles in the suspension to reduce the particle size. 


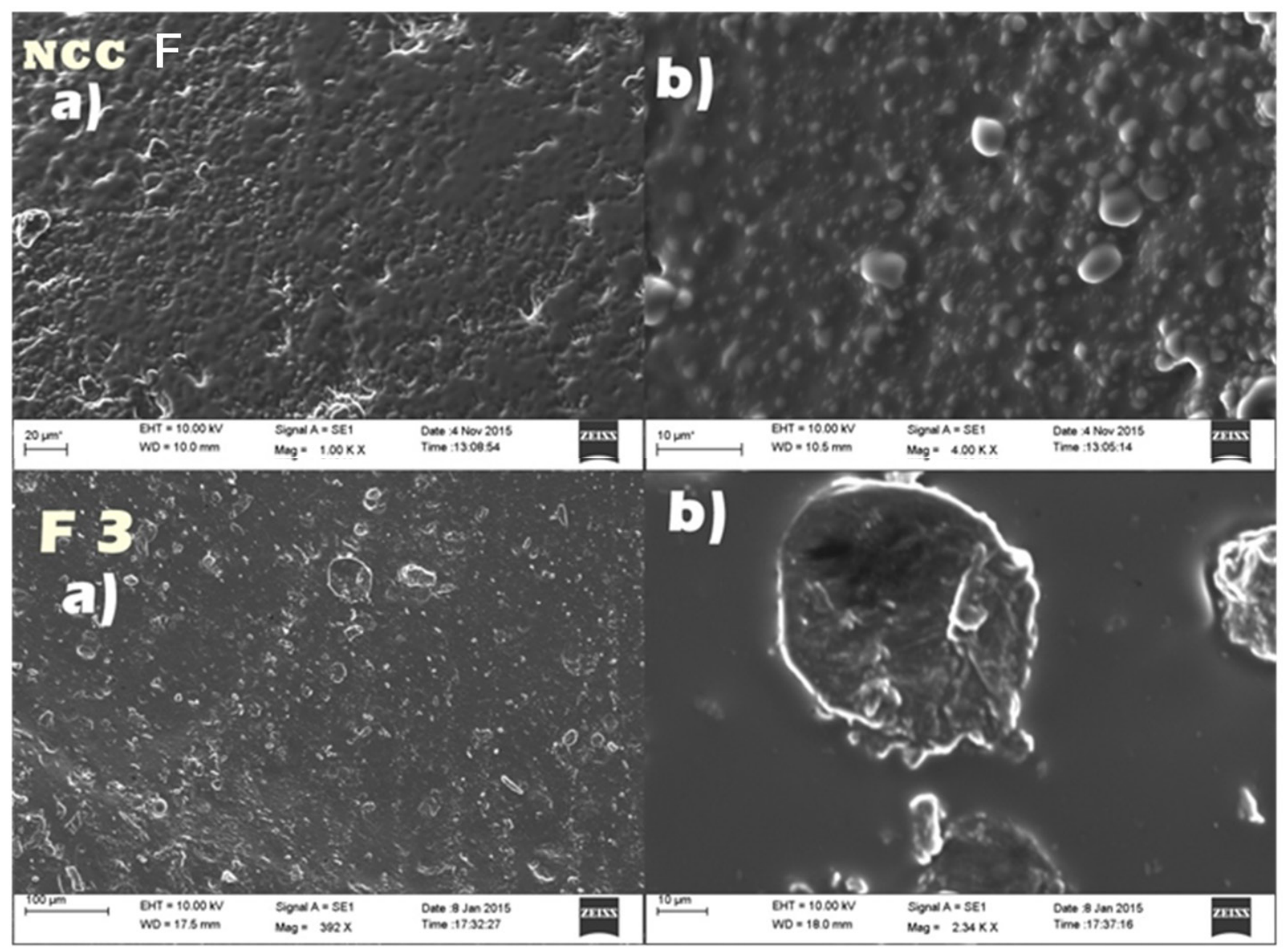

FIGURE 6 - SEM images (a) and its enlarged image (b) for NCC-F and F3 formulations.

TABLE IV - Particle size measurement NCC with different ultrasonic time points

\begin{tabular}{lccc}
\hline Sample name & Mean & S.D & Mode \\
\hline NCC 5 min & $452.0 \mathrm{~nm}$ & $56.5 \mathrm{~nm}$ & $438.2 \mathrm{~nm}$ \\
NCC $10 \mathrm{~min}$ & $222.2 \mathrm{~nm}$ & $26.3 \mathrm{~nm}$ & $224.5 \mathrm{~nm}$ \\
NCC $25 \mathrm{~min}$ & $2.1 \mathrm{~nm}$ & $0.3 \mathrm{~nm}$ & $2.0 \mathrm{~nm}$ \\
\hline
\end{tabular}



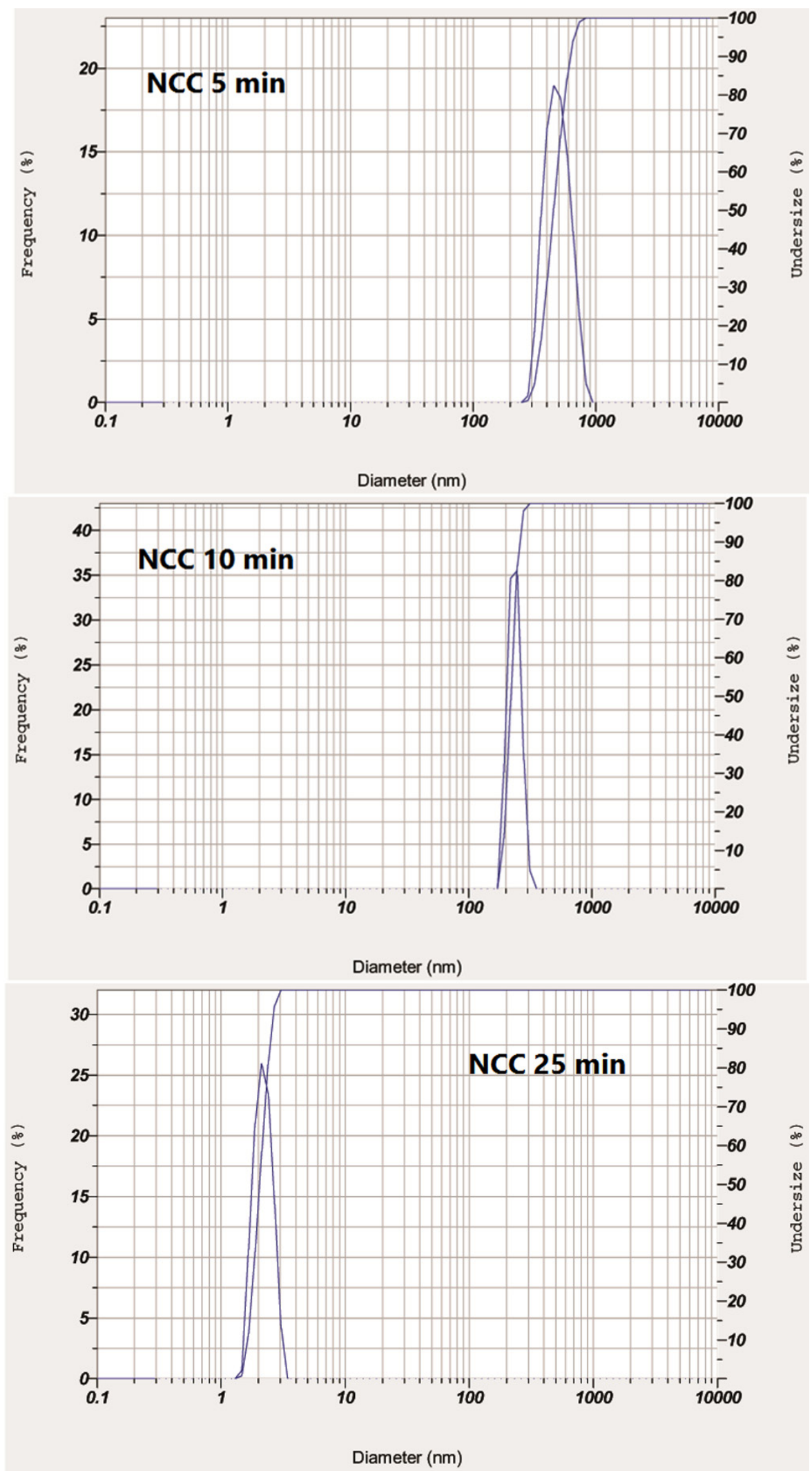

FIGURE 7 - Particle size analyser graphs for NCC polymer at different ultrasonic time points (5 min, 10 min and $25 \mathrm{~min}$ ). 


\section{Statistical studies}

The release mechanism of all the donepezil loaded thinfilms were determined by Higuchi model and Korsmeyer-Peppas applications as shown in Table V. The release kinetics of all the formulations were best suit for first order release kinetics. All the formulations were shown non-Fickian diffusion and $\mathrm{N}$ value were less than 1. This confirms drug release follows first order kinetics and it was mainly depends on disintegration/diffusion property of polymer and drug inside the medium.

TABLE V - Release kinetics models of different oral thinfilm Formulations

\begin{tabular}{lccl}
\hline $\begin{array}{l}\text { Formulation } \\
\text { Code }\end{array}$ & $\begin{array}{c}\text { Higuchi } \\
\text { kinetics } \\
\text { r2 }\end{array}$ & $\begin{array}{c}\text { Korsemeyer- } \\
\text { Peppas } \\
\text { equation } \\
\text { r2 }\end{array}$ & $\mathbf{~ N}$ \\
\hline F 1 & 0.921 & 0.864 & 0.501 \\
F 2 & 0.754 & 0.832 & 0.332 \\
F 3 & 0.847 & 0.748 & 0.415 \\
MCC-F & 0.709 & 0.816 & 0.337 \\
NCC-F & 0.836 & 0.829 & 0.407 \\
\hline
\end{tabular}

Note: regression coefficient (r2), diffusional exponent (n) for Korsmeyer-Peppas model

\section{In-Vitro drug dissolution studies}

Drug dissolution study was conducted to find the amount of drug dissolving in the medium at a certain point with desirable characteristic behaviour (Choi et al., 2012). Digital image of thinfilm is shown in Figure 8. In-Vitro dissolution profile data is represented in graph (Figure 9). From the results, the drug release pattern of various grades of cellulose derivatives were discussed and also correlated with the marketed formulation (Nagy, 2010). The cumulative percentage drug release of all the ODF formulations was increased gradually that was indicated in the figure.

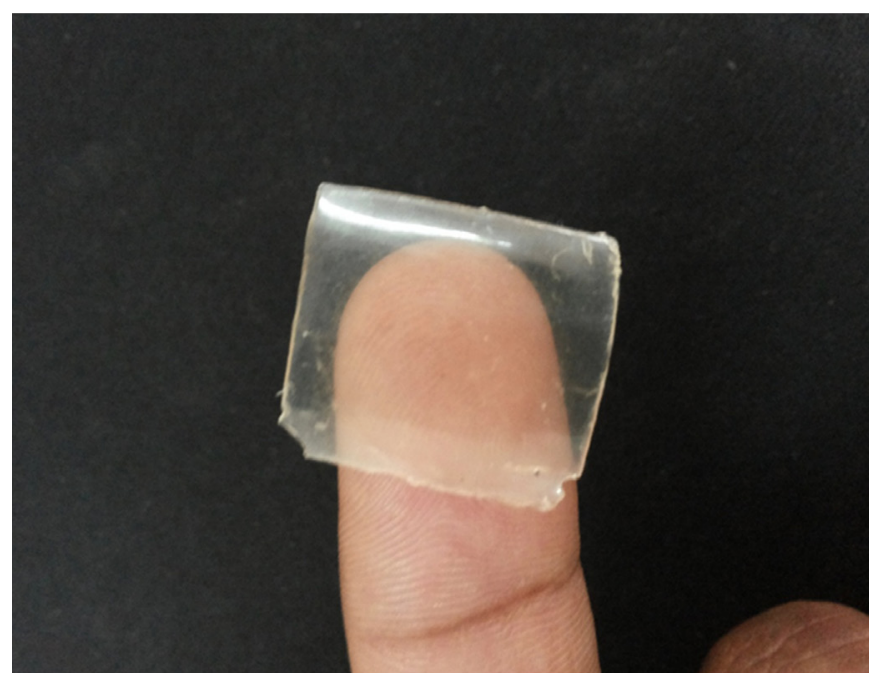

FIGURE 8 - Photograph to indicate a transparency of prepared ODF

From the figure 9, HPMC formulated film and MCC-F has been released promptly upto $42-70 \%$ in the span of $2.5 \mathrm{~min}(150 \mathrm{sec})$. In the period of $5 \mathrm{~min}(300$ $\mathrm{sec}$ ), the formulation F1, F2, F3 was released the drug upto $56.92,68.75$ and $72.84 \%$. But, $83.48 \%$ of the drug was released from the formulation MCC-F which was quite high in comparison with marketed formulation $(58.78 \%)$. In the case of NCC-F, Drastic drug release was achieved directly upto $92.27 \%$ in the period of 5 $\min (300 \mathrm{sec})$ without having interval. The $2.1 \mathrm{~nm}$ sized NCC particle has placed major role which release more drug $(94.53 \%)$ rapidly upto $5 \mathrm{~min}$. Prepared MCC and NCC formulations were shown faster drug disintegration time and drug release than other formulation which is due to nano and micro sizes of polymer present in the formulations. From the drug dissolution release graph, NCC-F formulation was achieved rapid dissolution than HPMC and MCC formulations. This was obtained mainly due to less particle size and high disintegration property in NCC-F formulation as compared with other formulation. These studies proved that nano sized hydrophilic cellulose polymers may dissolve freely and disintegrate the drug rapidly in the short span of time. Rapid drug disintegration of NCC was achieved because of higher surface roughness with maximum porous (proved from AFM) and the smaller particle size (300 $\mathrm{nm}$, proved from SEM). Hence, NCC-F formulation might be good alternate formulation for elder people who diagnosed with Alzheimer's disease. 


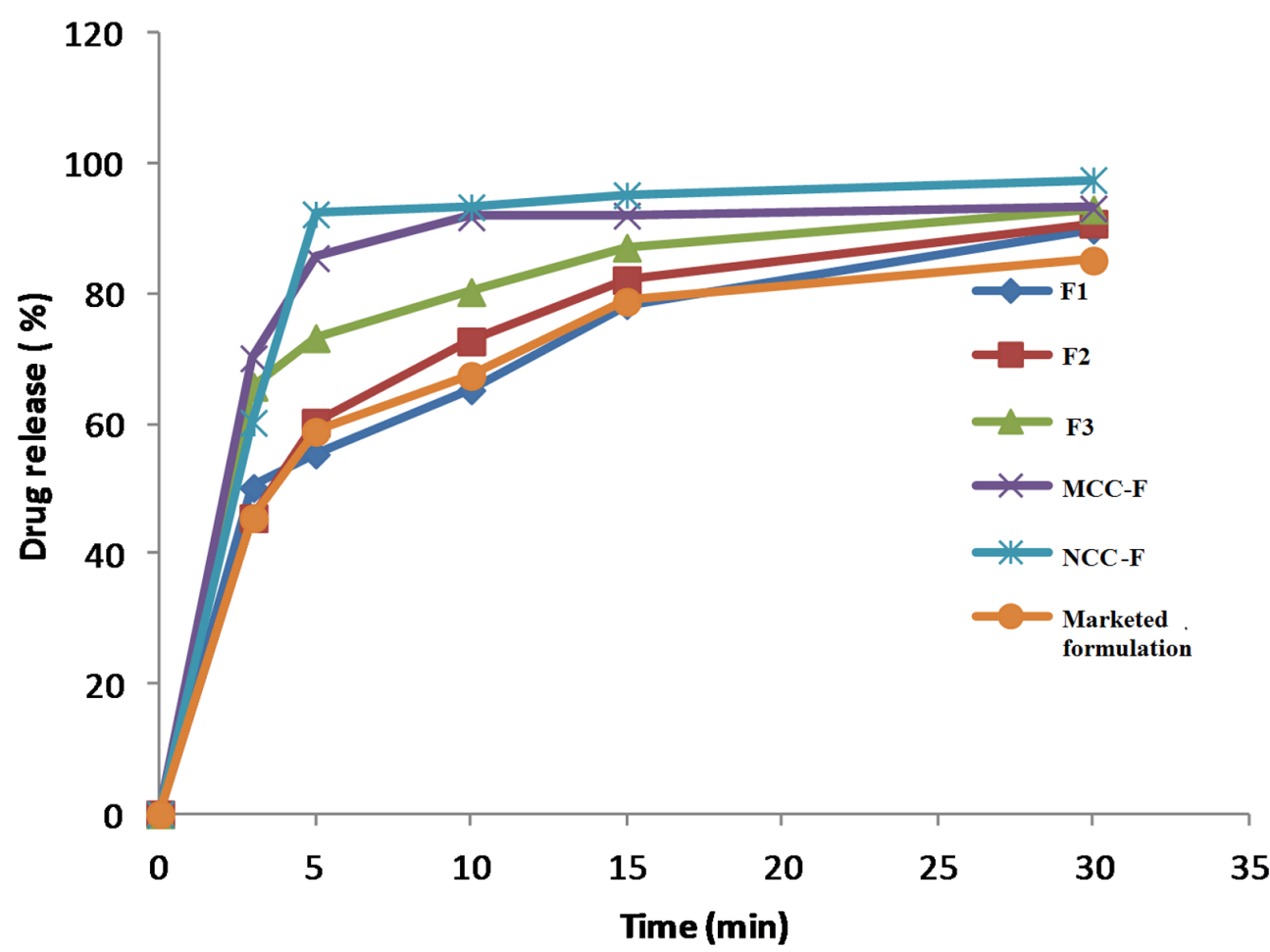

FIGURE 9 - In-vitro dissolution graphs for cellulose combined ODF formulations. All the results mentioned as mean $\pm \mathrm{SD}, \mathrm{n}=3$.

\section{In vivo animal studies}

Selected formulations with optimum physical characteristics and better in vitro dissolution behavior were conducted for in vivo drug absorption studies using male Wister rats. Formulations with HPMC 5cps (F3), microcrystalline cellulose (MCC-F) and nanocrystalline cellulose (NCC-F) were analyzed for drug plasma absorption studies with reference to marketed oral disintegrating tablets (ODT). Administered samples of donepezil (5 $\mathrm{mg} / \mathrm{kg}$ ) were evaluated by HPLC method (Abdelbary et al., 2014). The mean plasma concentration of marketed formulation was $16.959 \pm 3 \mathrm{ng} / \mathrm{mL}$ up to tmax of $4.9 \mathrm{~h}$. Mean plasma concentration of NCC-F formulation was $19.018 \pm 5 \mathrm{ng} / \mathrm{mL}$ in the span of $4 \mathrm{~h}$ and this was higher compared to MCC-F formulation. AUC $(0-\infty)$ of all the formulations were calculated by trapezoid method (Tayel et al., 2015). The results of all the formulations were shown the tmax in the order of MCC-F $<$ NCC-F $<$ F3 $<$ Marketed formulation with values as 3.8, 4.0, 4.2 and $4.9 \mathrm{~h}$. respectively. The plasma concentration in the order of NCC-F > MCC-F > F3 Marketed tablet formulation. Significant pharmacokinetic results were varied based on the polymer and its size inside the matrix/formulation. The total AUC $(0-\infty)$ of NCC-F formulation was $189.05 \pm 13 \mathrm{ng} / \mathrm{mL}$ and marketed formulation was about $132.05 \pm 54 \mathrm{ng} / \mathrm{mL}$. From these in vivo data, NCC-F has shown best drug absorption due to its particle size $300 \mathrm{~nm}$ and surface roughness 77.04 $\mathrm{nm}$. All the pharmacokinetic data were represented in Table VI. The moderate peak plasma concentration was observed in the case of MCC-F formulation and the total AUC $(0-\infty)$ was also near to the marketed formulation $(169.46 \pm 4)$. The relative bioavailability of NCC-F formulation was found to be $143.1 \%$ which was $40 \%$ higher than marketed ODT. The relative bioavailability of MCC-F was 127.1 and F3 was $114.3 \%$ which was measured from total area. All the formulations were shown optimum pharmacokinetic parameters with significant statistical value $(\mathrm{p} \geq 0.05)$. From the obtained plasma release graph (Figure 10), NCC-F formulation was shown extended $\mathrm{t} 1 / 2$ of 71.1 $\mathrm{h}$. Based on unique characteristic results obtained from physical and pharmacokinetic evaluations, NCC-F oral thin film will be best suited and potential alternate formulation for the treatment of Alzheimer's diseases. 
TABLE VI - Plasma concentration (in vivo) and pharmacokinetic parameters of final optimized ODF formulations. Oral administered $(5 \mathrm{mg} / \mathrm{kg})$ of drug

\begin{tabular}{lcccc}
\hline Formulation & $\mathbf{t}_{\max }(\mathbf{h})$ & $\mathbf{C}_{\max }(\mathbf{n g} / \mathbf{m L})$ & $\mathbf{A U C}_{(\mathbf{0}-\infty)}(\mathbf{n g} / \mathbf{m L})$ & $\mathbf{t}_{\mathbf{1} / 2}(\mathbf{h})$ \\
\hline F 3 & $4.2 \pm 2$ & $16.968 \pm 5$ & $151.02 \pm 12$ & $61.5 \pm 53$ \\
MCC-F & $3.8 \pm 2.1$ & $16.946 \pm 4$ & $167.95 \pm 55$ & $60.3 \pm 71$ \\
NCC-F & $4.05 \pm 3$ & $19.018 \pm 5$ & $189.05 \pm 13$ & $71.1 \pm 13$ \\
Marketed tablet & $4.97 \pm 1$ & $16.959 \pm 3$ & $132.05 \pm 54$ & $55.1 \pm 21$ \\
\hline
\end{tabular}

Note: Results represented as mean $\pm \mathrm{SD}$. $(\mathrm{n}=4) ;(\mathrm{p} \geq 0.05)$

tmax $=$ Time maximum, $\operatorname{Cmax}=$ Concentration maximum, $\operatorname{AUC}(0-\infty)=$ Area under plasma time curve from $0 \mathrm{~h} \mathrm{to} \infty \mathrm{h}$, $\mathrm{t} 1 / 2=$ Half of the drug concentration at the time

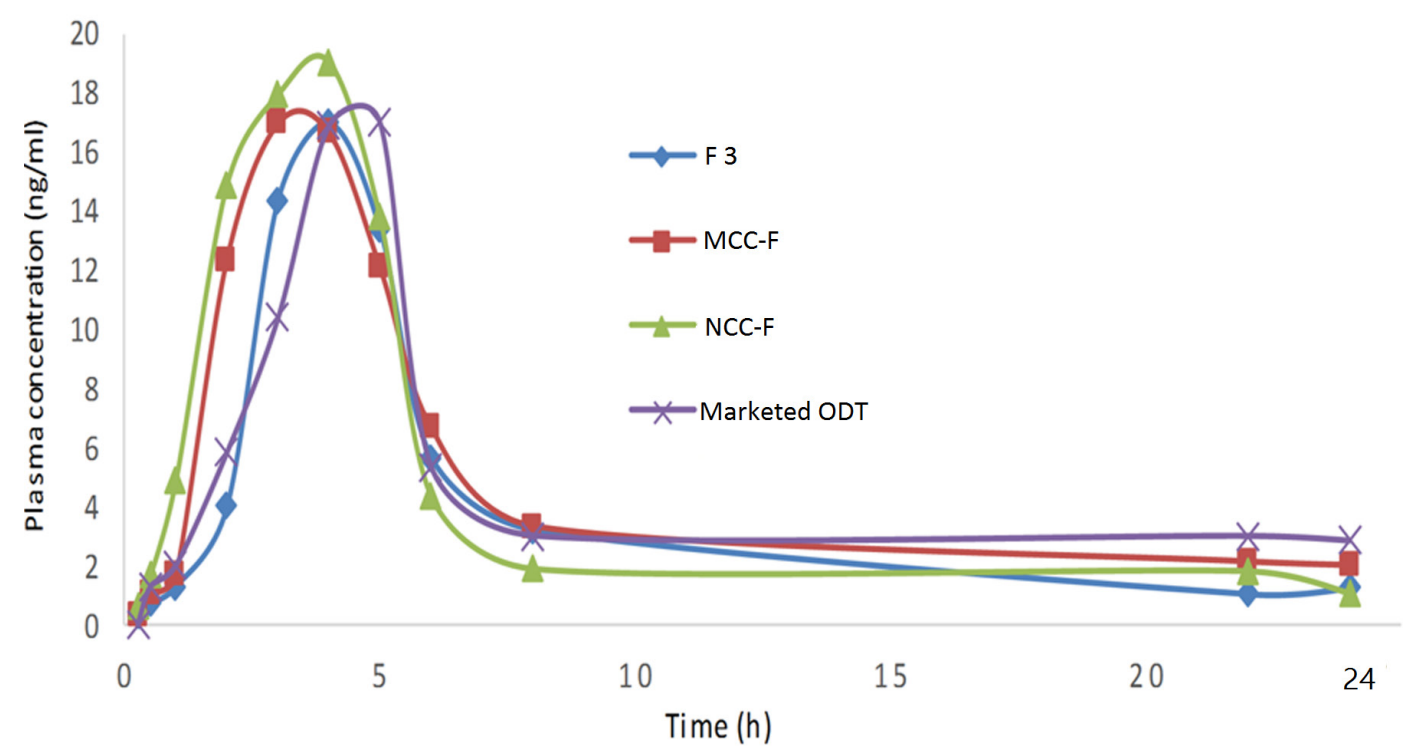

FIGURE 10 - In vivo bioavailability graph of oral dispersible films of F3, MCC-F, NCC-F with marketed oral disintegrating tablet towards male Wister rats, $\mathrm{n}=4$ and used drug $(5 \mathrm{mg} / \mathrm{kg})$ over $24 \mathrm{~h}$. Results represented as mean $\pm \mathrm{SD}, \mathrm{n}=4 ;(\mathrm{p} \geq 0.05)$ 


\section{CONCLUSION}

Oral disintegrating film was designed using donepezil hydrochloride mixed HPMC, MCC-F and NCC-F for observing rapid drug release property. The ODF film was well characterized with spectral (UV, FTIR, 1H-NMR) studies and microscopic (AFM and SEM) evaluations. Spectral analysis revealed that the hydrogen bonding interactions between polymer and drug. From the AFM analysis, surface roughness was higher for NCC than MCC and HPMC. The prepared ODF was achieved optimum thermal stability. Using in vitro drug release studies, NCC-F formulation was released the drug faster within 5 min on compared with MCC and HPMC formulation. In vitro dissolution studies and in vivo pharmacokinetic parameters confirmed that faster drug disintegration and higher bioavailability was achieved in NCC-F formulation than MCC-F, F3 and marketed formulations. Overall, nanosized NCC-F is best candidate for rapid drug release of Donepezil drug in the treatment of Alzheimer's disease.

\section{ACKNOWLEDGMENTS}

We are thankful to SIF-FIST, VIT University for providing laboratory, characterization facilities, and support to carry out present work. This article does not contain any studies with human subjects performed by any of the authors.

\section{REFERENCES}

Abdelbary A, Bendas ER, Ramadan AA, Mostafa DA. Pharmaceutical and pharmacokinetic evaluation of a novel fast dissolving film formulation of flupentixol dihydrochloride. AAPS PharmSciTech. 2014;15(6):1603-10.

Abdelbary G, Eouani C, Prinderre P, Joachim J, Reynier $\mathrm{J}$, Piccerelle P. Determination of the in vitro disintegration profile of rapidly disintegrating tablets and correlation with oral disintegration. Int J Pharm. 2005;292(1-2):29-41.

Atri A, Molinuevo JL, Lemming O, Wirth Y, Pulte I, Wilkinson D. Memantine in patients with Alzheimer's disease receiving donepezil: new analyses of efficacy and safety for combination therapy. Alzheimers Res Ther. 2013;5(1)6.

Bartha R, Smith M, Rupsingh R, Rylett J, Wells JL, Borrie MJ. High field 1H MRS of the hippocampus after donepezil treatment in Alzheimer disease. Prog Neuro Psycho Pharmacol Biol Psychiatry. 2007;32(3):786-93.
Brendan J, Kelley MD, Ronald C, Petersen. Alzheimer's disease and mild cognitive impairment. Neurol. Clin. 2007; 25(3):577-609.

Cheewakriengkrai L, Gauthier S. A 10-year perspective on donepezil. Expert Opin Pharmaco Ther. 2013;14(3)331-8.

Chen W, Yu H, Liu Y, Chen P, Zhang M, Hai Y. Individualization of cellulose nanofibers from wood using high-intensity ultrasonication combined with chemical pretreatments. Carbohydr.Polym1:2011;83(4):1804-11.

Choi J, Choi M-K, Chong S, Chung S-J, Shim C-K, Kim D-D. Effect of fatty acids on the transdermal delivery of donepezil: In vitro and in vivo evaluation. Int.J.Pharm.2012;422(1-2):83-90.

De Campos A, Correa AC, Cannella D, de M Teixeira E, Marconcini JM, Dufresne A et al. Obtaining nanofibers from curauá and sugarcane bagasse fibers using enzymatic hydrolysis followed by sonication. Cellulose. 2013;20(3):1491-500.

Dixit RP, Puthli SP. Oral strip technology: Overview and future potential. J Control Release. 2009;139(2):94-107.

Gaisford S,Verma A, Saunders M, Royall PG. Monitoring crystallisation of drugs from fast-dissolving oral films with isothermal calorimetry. Int J Pharm. 2009;380(1-2):105-11.

Garvie-Cook H, Frederiksen K,Petersson K, Guy RH, Gordeev S. Characterization of topical film-forming systems using atomic force microscopy and raman microspectroscopy. Mol Pharmaceutics. 2015;12(3):751-757.

Hebert LE, Scherr PA, Bienias JL, Bennett DA, Evans DA. Alzheimer disease in the US population. Arch Neurol. 2003;60(8):1119-1122.

Koch WF, Hauck WW, de Mars SS, Williams RL. Measurement science for food and drug monographs: toward a global system. Pharm Res. 2010;27:1203-1207.

Kumar, G. P., Phani, A., Prasad, R., Sanganal, J. S., Manali, N., Gupta, R., Rashmi, N., Prabhakara, G., Salins, C. P. and Sandeep, K. (2014), 'Polyvinylpyrrolidone oral films of enrofloxacin: Film characterization and drug release', International Journal of Pharmaceutics 2014:471(1):146-152.

Lange NA, Speight JG. Lange's Handbook of Chemistry, 16th ed., McGraw-Hill.

Letchford, Jackson, Wasserman B, Ye, Hamad W, Burt H. The use of nanocrystalline cellulose for the binding and controlled release of drugs. Int J Nanomedicine: 2011;6:321.

Liew KB, Tan YTF, Peh KK. Characterization of oral disintegrating film containing donepezil for alzheimer disease. AAPS Pharm Sci Tech. 2011;13(1):134-42. 
Molinuevo JL, Berthier ML, Rami L. Donepezil provides greater benefits in mild compared to moderate Alzheimer's disease: Implications for early diagnosis and treatment. Arch Gerontol Geriatr.2011;52(1):18-22.

Nagy ZK, Nyul, K, Wagner, I Molnar K, Marosi Gy. Electrospun water soluble polymer mat for ultrafast release of Donepezil HCl. Express Polym Lett. 2010;4(12):763-772.

Nishimura M, Matsuura K, Tsukioka T, Yamashita H, Inagaki $\mathrm{N}$, Sugiyama $\mathrm{T}$, et al. In vitro and in vivo characteristics of prochlorperazine oral disintegrating film. Int $\mathrm{J}$ Pharm. 2009;368(1-2):98-02.

Palla-Papavlu A, Rusen L, Dinca V, Filipescu M, Lippert T, Dinescu M. Characterization of ethylcellulose and hydroxypropyl methylcellulose thin films deposited by matrix-assisted pulsed laser evaporation. Appl. Surf. Sci. 2014;302:87-91.

Rao PR, Diwan PV. Formulation and in vitro evaluation of polymeric films of diltiazem hydrochloride and indomethacin for transdermal administration. Drug Dev Ind Pharm. 1998;24(4):327-36.

Rocca P, Cocuzza E, Marchiaro L, Bogetto F. Donepezil in the treatment of Alzheimer's disease Long-term efficacy and safety. Prog Neuro psychopharmacol Biol Psychiatry. 2002;26(2):369-373.

Rogers SL, Doody RS, Mohs RC, Friedhoff LT. Donepezil improves cognition and global function in Alzheimer disease: a 15-week, double-blind, placebo-controlled study. Donepezil Study Group. Arch Intern Med.1998;158(9):1021-1031.

Saluja S, Kasha PC, Paturi J, Anderson C, Morris R, Banga AK. A novel electronic skin patch for delivery and pharmacokinetic evaluation of donepezil following transdermal iontophoresis. Int.J.Pharm.2013;453(2):395-9.
Sayed S, Ibrahim HK, Mohamed MI, El-Milligi MF. Fastdissolving sublingual films of terbutaline sulfate: Formulation and In vitro/In VivoEvaluation. Mol.Pharm.2013;10(8):2942-7.

Scoutaris N AFM in Advanced Pharmaceutical Technology. Pharm Anal Acta. 2012;3(8):1-2.

Shen, C.-y., Yuan, X.-d., Bai, J.-x., Lv, Q.-y., Xu, H., Dai, L., Yu, C., Han, J. and Yuan, H.-1. Development and characterization of an orodispersible film containing drug nanoparticles. European Journal of Pharmaceutics and Biopharmaceutics. 2013:85(3):1348-1356.

Shoaib MH, Tazeen J, Merchant HA, Yousuf RI. Evaluation of drug release kinetics from ibuprofen matrix tablets using HPMC. Pak J Pharm Sci. 2006;19(2):119-24.

Song Y, Yang X, Chen X, Nie H, Byrn S, Lubach JW. Investigation of drug-excipient interactions in lapatinib amorphous solid dispersions using solid-state NMR spectroscopy. Mol Pharm. 2015;12(3):857-66.

Tang Y, Yang S, Zhang N, Zhang J. Preparation and characterization of nanocrystalline cellulose via low-intensity ultrasonic-assisted sulfuric acid hydrolysis. Cellulose. 2014;21(1):335-346.

Tayel SA, El Nabarawi MA, Amin MM, Abou Ghaly MH. Sumatriptan succinate sublingual fast dissolving thin films: formulation and in vitro/in vivo evaluation. Pharm Dev Technol. 2015;21(3)328-37.

Yamamoto Y, Fujii M, Watanabe K, Tsukamoto M, Shibata Y, Kondoh M, et al. Effect of powder characteristics on oral tablet disintegration. Int.J.Pharm.2009;365(1-2):116-20.

Received for publication on $01^{\text {st }}$ December 2017 Accepted for publication on $16^{\text {th }}$ May 2019 